In future studies we shall note the brand of cigarette smoked, for this will determine the nicotine yield per cigarette. This clearly will influence the correlation between urinary cotinine: creatinine ratios and the number of cigarettes smoked each day and, in the current study, may explain some of the scatter.

We suggest that simultaneous assays of urinary nicotine and cotinine could be a useful index of current smoking habits and that the slower disappearance of cotinine from the urine will facilitate identifying smokers who attempt to conceal their habit by abstaining from smoking on the day of their clinic visit.

We should like to thank Mr E J Collin, of John Player and Sons, Nottingham, for arranging the supplies of cotinine; Mr A Bridge, principal biochemist, University Hospital, Nottingham, for technical guidance; Professor J R A Mitchell for his helpful criticism; and Mrs Jayne Webster for typing the manuscript.

\section{References}

${ }^{1}$ Doll, R, and Hill, A B, National Cancer Institute Monographs, 1966, 19, 205.

${ }^{2}$ Hammond, E C, and Garfinkel, L, Archives of Environmental Health, 1969, 19, 167.

${ }^{3}$ Gordon, T, Kannel, W B, and McGee, D, Lancet, 1974, 2, 1345.

4 Wilhelmsson, C, et al, Lancet, 1975, 1, 415.

5 Doll, R, and Peto, R, British Medical fournal, 1976, 2, 1525.

${ }^{6}$ Sillett, R W, et al, British Medical fournal, 1978, 2, 1185.

7 Vogt, T M, et al, American fournal of Public Health, 1977, 67, 545.

${ }^{8}$ Russell, M A H, and Feyerabend, C, Lancet, 1975, 1, 179.

${ }^{9}$ Beckett, A H, and Triggs, E J, Nature, 1966, 211, 1415.

${ }^{10}$ Kivela, E W, in Manual of Toxicology, ed I Sunshine, p 252. Cleveland, Ohio, CRC Press Inc, 1971.

11 Burt, A, et al, Lancet, 1974, 1, 304.

12 Jones, R D, Commins, B T, and Cernik, A A, Lancet, 1972, 2, 302.

13 Russell, M A H, Cole, P V, and Brown, E, Lancet, 1973, 1, 576.

(Accepted 14 August 1979)

\title{
Return to work and quality of life after surgery for coronary artery disease
}

\author{
STEPHEN WESTABY， RALPH N SAPSFORD， HUGH H BENTALL
}

British Medical fournal, 1979, 2, 1028-1031

\section{Summary and conclusions}

Changes in work capability and quality of life were assessed retrospectively in 130 patients with ischaemic heart disease who had undergone aortocoronary bypass operations during 1976-7 because of medically uncontrollable angina.

A total of 85 patients $(65.4 \%)$ reported complete relief from angina six months after operation, though 12 later suffered a recurrence. Substantially fewer patients needed drugs after the operation. Before operation 9 out of 117 men fully employed at the onset of angina were working without restriction or doing lighter, fulltime work, 38 were at work but seriously incapacitated by angina, and 70 were forced to stop work. After operation 70 were working without restriction or engaged in lighter work, 15 were at work but still restricted by angina, and only 32 were forced to stop work. This result was highly significant $(P<0.001)$. These differences were even more pronounced in heavy manual workers, of whom none could work normally before operation, whereas 16 were working without restriction afterwards. Of patients wishing to engage in hobbies or sports, social activity, and sexual intercourse but were restricted before operation, about two-thirds could resume these activities afterwards.

Royal Postgraduate Medical School, Hammersmith Hospital, London W12 0HS

STEPHEN WESTABY, BSC, FRCS, registrar in cardiothoracic surgery (now locum senior registrar in cardiothoracic surgery, Harefield Hospital, Harefield, Middlesex)

RALPH N SAPSFORD, CHM, FRCS, consultant and senior lecturer in cardiothoracic surgery

HUGH H BENTALL, MB, FRCS, professor of cardiac surgery and honorary consultant thoracic surgeon
Coronary artery surgery provided dramatic symptomatic relief in up to $90 \%$ of patients and permitted rehabilitation and return to gainful employment irrespective of type of labour. The degree of symptomatic improvement and increase in exercise tolerance after successful surgery is usually far greater than occurs with any other form of treatment and directly improves quality of life and work capability.

\section{Introduction}

Coronary artery disease is a major cause of death and disability in men aged 35-65 years, who are traditionally regarded as the most economically productive members of society. ${ }^{1}$ Its manifestations include sudden death, myocardial infarction, heart failure, and angina pectoris. Although many patients respond to medical management, the development of aortocoronary bypass grafting using the saphenous vein over the past 10 years offers a new and increasingly acceptable approach, especially for the severely handicapped. Many large series have shown benefit in terms of pain relief, ${ }^{2}$ prevention of myocardial infarction, ${ }^{3}$ and improvement in ventricular function. ${ }^{4}$ There is also evidence of increased longevity. ${ }^{5}$ Although early reports showed fewer patients working after operation than before, ${ }^{6}$ ? later results were encouraging. ${ }^{8} 9$

We have investigated the quality of life and work capability of patients before and after operations performed in this hospital during 1976-7.

\section{Patients and methods}

Patients were selected for operation after failure to control their angina by standard medical treatment and elimination of risk factors. A total of 156 patients underwent coronary artery bypass grafting during the two years, of whom nine had been operated on before. Three of the patients also underwent resection of a left ventricular aneurysm. Of the 14 known deaths, two occurred in hospital and 12 after 30 days. Nine patients died of their disease without returning to work, one died after pneumonectomy for carcinoma of the bronchus, and another died after an aortofemoral bypass operation for peripheral 
arterial disease. Three patients died after returning to full-time employment: one died of myocardial infarction, another was hit by a car, and the third took his own life, finding persistent angina intolerable. The remaining 142 patients were therefore investigated.

Each patient was sent a questionnaire asking about pain relief, drug requirements, ability to work, and recreational, social, and sexual activity before and after operation. A total of 121 men and nine women replied. Ages ranged from 34 to 69 years and follow-up from 9 to 33 months (mean 16.5 months). Of the 12 patients lost to follow-up, some may have died; eight lived abroad.

Of the men available for study, 117 were fully employed at the onset of angina, and their work capability was examined in detail. The remaining patients-five housewives, four men who had retired before the onset of limiting angina, and four working women-were considered separately. Work capability was classified as $(a)$ working without restriction, $(b)$ at work but restricted by angina, and $(c)$ forced

TABLE I-Subjective assessment by 130 patients of relief from angina six months after coronary artery bypass grafting

\begin{tabular}{lcccc}
\hline & $\begin{array}{c}\text { Complete } \\
\text { relief }\end{array}$ & $\begin{array}{c}\text { Considerable } \\
\text { improvement }\end{array}$ & $\begin{array}{c}\text { Moderate } \\
\text { improvement }\end{array}$ & $\begin{array}{c}\text { No } \\
\text { improvement }\end{array}$ \\
\hline No (\%) of patients & $85(65 \cdot 4)$ & $31(23 \cdot 8)$ & $11(8.5)$ & $3(2 \cdot 3)$ \\
\hline
\end{tabular}

TABLE II-Drug requirements before and after operation (125 patients)

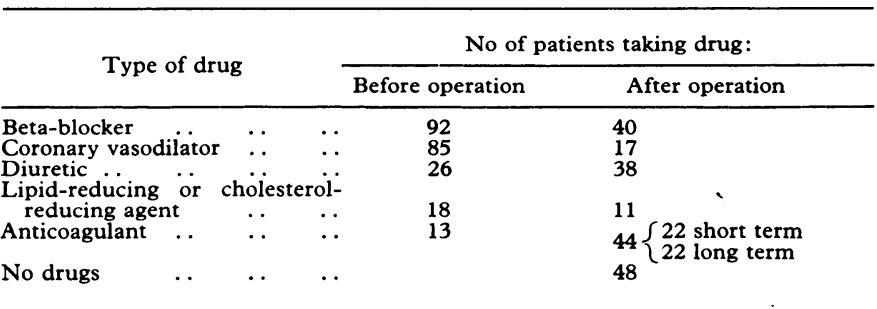

TABLE III-Occupational grouping and mean age (years) of 117 men in full-time employment at onset of angina

\begin{tabular}{lcccc}
\hline & $\begin{array}{c}\text { Heavy } \\
\text { manual } \\
\text { workers }\end{array}$ & $\begin{array}{c}\text { Skilled } \\
\text { workers and } \\
\text { tradesmen }\end{array}$ & $\begin{array}{c}\text { Clerical } \\
\text { workers }\end{array}$ & $\begin{array}{c}\text { Executives } \\
\text { and } \\
\text { professionals }\end{array}$ \\
\hline $\begin{array}{l}\text { No of patients } \ldots \\
\text { Mean age } \pm \text { SD } \ldots\end{array}$ & $50.8 \pm 8.9$ & $53.0 \pm 7.1$ & $53.1 \pm 6.9$ & $50.9 \pm 9.5$
\end{tabular}

TABLE IV-Work capability before and after operation of 117 men in full-time employment at onset of angina

\begin{tabular}{|c|c|c|}
\hline & Before operation & After operation \\
\hline 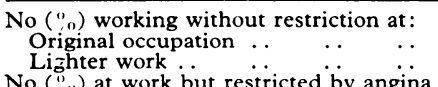 & $\left.\begin{array}{ll}\ldots & 8 \\
. & 1\end{array}\right\} \begin{array}{l}9(7 \cdot 7) \\
38(32 \cdot 5)\end{array}$ & $\left.\begin{array}{r}61 \\
9\end{array}\right\} 70 \quad(59 \cdot 8)$ \\
\hline No (" & $70(59.8)$ & $32 *(27 \cdot 4)$ \\
\hline
\end{tabular}

*Two patients aged 63 and 65 retired after operation but were angina-free. to stop work. Patients were considered fit for work if their angina was completely abolished or considerably improved three months after operation.

Patients were classified as (a) heavy manual workers, (b) skilled workers and tradesmen, $(c)$ clerical workers, or $(d)$ executives and professionals according to the physical demands and responsibility of their occupations. We rejected other methods of classification, including social class, since these failed to express adequately the degrees of physical exertion or psychological pressures concerned, which are important precipitating factors in angina pectoris.

\section{Results}

RELIEF FROM ANGINA

Of the 130 patients, only three reported no improvement in angina six months after operation. In contrast, 85 patients $(65 \%)$ reported complete relief, $31(24 \%)$ considerable improvement, and $11(9 \%)$ moderate improvement (table I).

Of the patients reporting complete relief at six months, $12(14 \%)$ suffered a recurrence of angina. This occurred 6-12 months after operation in five cases and over 12 months later in seven, the mean interval without angina being 11.7 months. The angina was graded as less severe than before by eight patients, of the same severity by one, and more severe by three.

\section{DRUG REQUIREMENTS}

Data on drugs required before and after operation were obtained from 125 patients (table II). Before operation all patients needed beta-blockers or coronary vasodilators or both to control their angina. Twenty-six patients took a diuretic. After operation substantially fewer patients needed treatment for relief of pain, although more received an anti-heart-failure regimen.

\section{WORK CAPABILITY}

Men fully employed at onset of angina-table III gives the occupational grouping and mean ages of the 117 men who were in full-time employment at the onset of angina. Before operation nine men $(8 \%)$ were working without restriction or had changed to physically less demanding work, $38(33 \%)$ were working but restricted by angina, and $70(59.8 \%)$ had been forced to stop work. After operation, however, $70(60 \%)$ were working without restriction or engaged in lighter work, 15 (13\%) were working but restricted by angina, and only $32(27 \%)$ were unable to work. These differences were significant ( $\mathrm{P}<0.001 ; \chi^{2}$ test) (table IV). The most striking difference occurred in the work capability of heavy manual workers, none of whom could work normally before operation, whereas two-thirds could do so afterwards (table V). Table VI shows the time spent off work before and after operation in each occupational group. The median stay in hospital in each group was 14.0 days (range 10-39 days).

Housewives, retired men, and working women-Of the five housewives severely handicapped by angina before operation, all resumed housework to their own satisfaction afterwards. Similarly, the four retired men became angina-free with a corresponding increase in activity. Of the four women in full-time employment, all were restricted before operation and one was forced to stop work. This patient retired after operation, though the others returned to full-time employment.

TABLE V-Work capability of 117 men before and after operation related to occupation. Percentages in parentheses

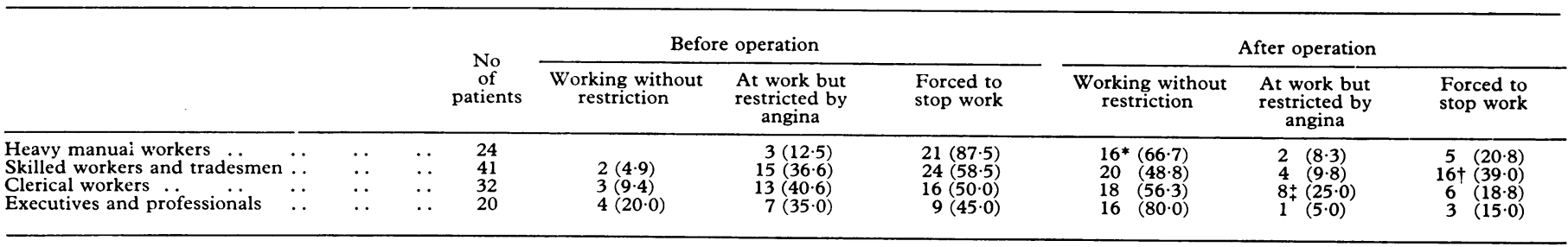

*One patient retired at 65 but was angina-free. 
TABLE VI-Time off work (months) before and after operation related to occupation (117 men)

\begin{tabular}{|c|c|c|c|c|c|}
\hline & & \multicolumn{2}{|c|}{ Before operation } & \multicolumn{2}{|c|}{ After operation* } \\
\hline & & Range & Median & Range & Median \\
\hline \multicolumn{6}{|l|}{ Heavy manual workers in: } \\
\hline $\begin{array}{lll}\text { Original work } & \ldots & \ldots \\
\text { Lighter work } & \ldots\end{array}$ & 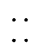 & $0-60$ & $5 \cdot 0$ & $\begin{array}{l}3-15 \\
3-9\end{array}$ & $\begin{array}{l}5 \cdot 0 \\
3.0\end{array}$ \\
\hline Skilled workers and tradesmen & $\therefore$ & $0-180$ & $5 \cdot 0$ & $1-12$ & $4 \cdot 0$ \\
\hline Clerical workers $\ldots$ & .. & $0-12$ & 1.5 & $2-18$ & $4 \cdot 0$ \\
\hline Executives and professionals & .. & $0-9$ & $2 \cdot 0$ & $1-6$ & $3 \cdot 0$ \\
\hline
\end{tabular}

*Excluding those who were forced to stop work or retired.

\section{CHANGES IN RESTRICTION OF ACTIVITY}

Table VII shows the changes in restriction of recreational, social, and sexual activity after operation. From the comments of angina-free patients pain relief clearly provided the basis for a "new lease of life."

TABLE VII-Restriction of activity before and after operation in all 130 patients

\begin{tabular}{|c|c|c|c|c|c|}
\hline & & & & $\begin{array}{l}\text { Patients restricted } \\
\text { before operation* }\end{array}$ & $\begin{array}{l}\text { Patients restricted } \\
\text { after operation }\end{array}$ \\
\hline $\begin{array}{l}\text { Hobbies or sports } \\
\text { Gardening .. } \\
\text { Social activity.. } \\
\text { Sexual intercourse }\end{array}$ & $\begin{array}{l}\ldots \\
\cdots \\
\cdots\end{array}$ & $\begin{array}{l}\cdots \\
\cdots \\
\cdots\end{array}$ & $\begin{array}{l}\cdots \\
\cdots \\
\cdots\end{array}$ & $\begin{array}{r}113(130) \\
112(112) \\
116(130) \\
99(103)\end{array}$ & $\begin{array}{l}38 / 113\left(29 \cdot 2^{\circ}{ }_{0}^{\circ}\right) \\
35 / 112\left(31 \cdot 3^{\circ}\right) \\
30 / 116\left(23 \cdot 1^{\circ}{ }_{0}^{\circ}\right) \\
29 / 99\left(28 \cdot 2^{\circ}{ }_{0}\right)\end{array}$ \\
\hline
\end{tabular}

*Figures in parentheses are numbers who indulged in the activity before illness.

The percentage of patients restored to unrestricted activity closely paralleled the incidence of complete pain relief, although patients with symptoms of less severity were equally keen to pursue their activities within the lessened confines of their angina.

\section{Discussion}

Saphenous vein aortocoronary bypass operations have been used for 10 years, and many studies have shown low operative mortality and improved survival in patients with left main coronary stenosis and medically refractory unstable angina. ${ }^{10}$ Relief of angina is the most readily apparent benefit and is usually evident within three weeks, when patients test themselves in the hospital environment. Mundth and Austen ${ }^{2}$ summarised the experience of over 10000 patients from 16 centres, of whom $60-70^{\circ}$ obtained complete anginal relief and no longer required medical treatment. Other centres confirmed their findings, and our series compared favourably, $65 \%$ of patients reporting complete relief and $24^{\circ} \%$ considerable improvement.

Pain relief provides the basis for rehabilitation, return to work, and reversion of lifestyle. In our series four out of five patients dependent on glyceryl trinitrate (trinitrin) stopped taking this after discharge from hospital, more than half stopped beta-blockers, and 48 needed no further medical treatment. Initially some patients were formally anticoagulated with a short course of warfarin, but later patients were encouraged to take an antiplatelet agent such as dipyridamole, sulphinpyrazone, or soluble aspirin. More patients received treatment for heart failure after operation, occasionally as a result of perioperative infarction but also because of reluctance to discontinue a regimen begun in the postoperative period for dysrhythmias or salt-and-water retention after cardiopulmonary bypass. Freedom from reliance on drugs and the necessity to carry and constantly renew supplies provided a considerable psychological boost to these patients.

Absence of work, despite or as part of intensive medical treatment for angina, results in financial difficulty, anxiety, and demoralisation for the patient and his family, who become increasingly dependent on the State for sickness benefit, hospital facilities, and medicine. Intermittent loss of manpower and productivity may also be expensive for the employer. Though $40 \%$ of patients in our series continued to work within the confines of their angina, only $8^{\circ}{ }_{\circ}$ considered themselves to work normally. Fifty-nine per cent of patients stopped work completely, and at the time of operation the average duration of sick leave varied from 16 months for heavy manual workers to three months for less demanding clerical work. Patients with complete relief of pain or considerable improvement were encouraged to return to work after three months when their median sternotomy was firmly united. Of $117 \mathrm{men}, 85(73 \%)$ returned to full employment, $70\left(60^{\circ}{ }_{0}\right)$ performing normal duties to their complete satisfaction. The remainder were incapacitated to varying degrees, 10 by persistent or recurrent angina and five by surgical sequelae, either sternal instability, incisional hernia, or painful swelling of the legs. Eight patients changed to lighter work, seven of whom were manual workers in considerably demanding occupations. Remarkably, $75 \%$ of heavy manual workers were fully employed after operation, all within 15 months and most within six months after discharge from hospital. One returned to deep-sea fishing after a five-year lay-off. Twelve patients with complete symptomatic relief for at least six months subsequently suffered recurrent angina, and although all 12 had returned to work, three were eventually forced to retire.

Patients in this study were referred from a wide area of southern England and Wales, with a few from overseas, and although our experience proved similar to that of Wallwork et al in Glasgow, ${ }^{9}$ it differed from reports from the United States. Barnes et $a l^{6}$ reported a $10^{\circ}{ }_{0}$ return to work one year after operation in patients not working beforehand and only a $16^{\circ}$ o return to work among patients working full-time until operation, resulting in a loss to the workforce. English et al ${ }^{7}$ found that $75 \%$ of private but only $32 \%$ of Veterans Administration Hospital patients returned to full-time employment and that return was closely related to work capability within three months of operation. Rimm ${ }^{8}$ more encouragingly reported a $90 \%$ return to work in patients aged under 55 who were fully employed up to the time of operation, but only $20^{\circ}$ of patients forced to stop before operation returned afterwards. Since results for immediate relief are comparable, the British patient must be better motivated to return to work, or his physician more inclined to encourage him.

After prolonged suffering from angina with restricted physical activity, avoidance of excitement, and abstinence from sexual intercourse our patients showed the pronounced alteration in lifestyle possible after successful grafting and pain relief. Ninety-six per cent of patients who had been sexually active at the onset of symptoms were restricted by angina, despite prophylactic trinitrin. After operation $70 \%$ were restored to previous activity, though shortness of breath or hesitancy and concern on behalf of the partner remained as prohibiting factors. Two-thirds resumed hobbies or sports and could enjoy sucial activities to a degree comparable to that before the onset of symptoms. Indeed, many patients took on a "new lease of life" after months or years of disablement. Golf, swimming, dancing, and squash were popular new activities. Many patients, however, were grateful to manage simple tasks like gardening, cleaning the car, or playing with the children, which had been impossible before.

The pool of patients awaiting coronary artery operations is thought to be about $400 /$ million population with about 150 new patients/million population being added yearly. ${ }^{11}$ In Great Britain limited resources restrain demand. During 1976-7 fewer than 4000 such operations were performed in England and Wales. It is estimated that the average cost of the operation is $£ 3000$ and that this would be recouped within one year by elimination of sickness benefit, increased productivity, and reduction in cost of medicines and hospital admission. In contrast to other types of patient requiring intensive care facilities, however, increased allocation of resources may well 
be justified by cost-effectiveness as well as by the enhanced quality of life.

\section{References}

${ }^{1}$ Fuchs, V R, Who Shall Live? Health, Economics, and Social Choice. New York, Basic Books Inc, 1974.

${ }^{2}$ Mundth, E E, and Austen, W G, New England fournal of Medicine, $1975,293,13,75,124$

3 Spencer, F C, Isom, O W, and Glassman, E, Annals of Surgery, 1975, 180, 439.

${ }^{4}$ Miller, R R, American fournal of Cardiology, 1975, 35, 11.
5 Johnson, W D, and Kayser, K L, Annals of Thoracic Surgery, 1973, 16, 1. 6 Barnes, G K, et al, Circulation, 1975, 52, suppl No 2, p 118.

${ }^{7}$ English, M T, et al, Circulation, 1975, 52, suppl No 2, p 144.

${ }^{8}$ Rimm, A A, fournal of the American Medical Association, 1976, 236, 361.

' Wallwork, J, Potter, B, and Caves, P K, British Medical fournal, 1978, 2 1680.

10 Tokaro, T, Hultgren, H, and Detre, K, Circulation, 1976, 54, suppl No 3, p 107.

11 Working Group on Long-term Effects of Coronary Bypass Surgery, The Hague, 1-4 November 1977. Copenhagen, WHO Regional Office for Europe, 1978.

(Accepted 14 August 1979)

\section{Improving medication compliance: a randomised clinical trial}

\section{STAFFAN E NORELL}

British Medical fournal, 1979, 2, 1031-1033

\section{Summary and conclusions}

A medication monitor which recorded the date and hour each time a medicine bottle was opened was used to evaluate a programme for improving patients' compliance with their treatment. Eighty-two patients with glaucoma who had been prescribed pilocarpine eye drops three times daily to prevent visual loss were randomised into two groups. Both groups used the medication monitor during two 20 -day periods, but before the second period the experimental group were given an education and tailoring programme in an attempt to improve their compliance. Nine patients missed the second treatment period and were excluded from the analysis. The patients in the experimental group showed significantly improved compliance when compared with the control group. The numbers of missed doses were reduced by about half, as was the proportion of time that exceeded the eight-hour dose intervals.

Follow-up studies are needed to determine how long the improved compliance persists, but anyone considering setting up an education and tailoring programme should recognise the extent to which therapeutic efforts are wasted because of non-compliance.

\section{Introduction}

In recent years studies of patient compliance have directed attention to the patient's role in drug treatment. Diagnostic and therapeutic efforts are of little value unless the prescribed regimen is followed by the patient, and non-compliance has been recognised as "a major problem in our health care system."

Different strategies have been suggested to improve patients' compliance. These include efforts to increase the patient's knowledge and understanding of his disease and its treatment and attempts to integrate or "tailor" the regimen into the

\footnotetext{
Department of Social Medicine, Karolinska Institutet, Huddinge University Hospital, Huddinge, Sweden

STAFFAN E NORELL, MD, physician
}

patient's daily life. But little is known about the effectiveness of these measures in improving compliance, and Sackett et al have argued that such strategies should be evaluated in controlled trials. ${ }^{2}$ The cost-effectiveness of improving medication compliance has been discussed by Stason and Weinstein. ${ }^{3}$

Our aim was to evaluate an education and tailoring programme for patients with glaucoma in a randomised clinical trial based on objective and detailed information about the patients' drug taking.

\section{Patients and methods}

The series comprised patients treated with pilocarpine for chronic simple glaucoma at the eye clinic of Huddinge University Hospital. All had glaucomatous visual field defects, cupping of the optic disc, and raised intraocular pressures, and all were prescribed pilocarpine eye drops three times daily in an eye with visual acuity of at least 2/60. Data were collected from March 1977 to November 1978. A total of 82 patients, 45 men and 37 women, aged 56-90 (median 73) years met the criteria at the time of their entry into the study. They were stratified for age and randomly allocated to an experimental group or a control group.

The patients' behaviour in using the eye drops was studied with a medication monitor which recorded the date and hour each time the medication bottle was opened.

The monitor (fig 1) consisted of a plastic box with a holder for a $25-\mathrm{ml}$ medicine bottle. The holder was designed to protect the bottle and to facilitate replacement of the eyedropper cap. An elastic flap linked to a microswitch inside the box signalled to the electronic part of the monitor whether the cap was on or off. A sliding lid in the bottom of the monitor could be removed to exchange the bottle and battery but it was sealed when the monitor was given to the patients. The electronic system recorded information on whether or not the bottle had been opened during the last hour. When the monitor was connected to a separate read-out device this information, together with a time signal, was displayed on an electrocardiographic recorder.

Study periods-Recordings were made over three weeks between two visits to the eye clinic. The days of the visits were excluded, leaving a monitored record of 20 days for each patient. At the second visit to the clinic the patients in the experimental group underwent a 30-minute patient education and tailoring programme, and all patients then used the monitor to record their drug taking for a further 20 days.

Patient education-Basic information on the disease and its treatment was supplied by a tape-slide show and by leaflet. An ophthalmology assistant checked the patient's knowledge and understanding and re-emphasised insufficiently mastered information. The patients were encouraged to ask questions and discuss problems about their own medication. 